\title{
Stability Analysis of High-Order Iterative Learning Control for a Class of Nonlinear Switched Systems
}

\author{
Xuhui Bu, ${ }^{1,2}$ Fashan Yu, ${ }^{1}$ Ziyi Fu, ${ }^{1}$ and Fuzhong Wang ${ }^{1}$ \\ ${ }^{1}$ School of Electrical Engineering \& Automation, Henan Polytechnic University, Jiaozuo 454003, China \\ ${ }^{2}$ Henan Provincial Open Laboratory for Control Engineering Key Discipline, Henan Polytechnic University, Jiaozuo 454003, China \\ Correspondence should be addressed to Xuhui Bu; buxuhui@gmail.com
}

Received 22 March 2013; Revised 18 June 2013; Accepted 18 June 2013

Academic Editor: Josef Diblík

Copyright (c) 2013 Xuhui Bu et al. This is an open access article distributed under the Creative Commons Attribution License, which permits unrestricted use, distribution, and reproduction in any medium, provided the original work is properly cited.

\begin{abstract}
This paper considers the stability of high-order PID-type iterative learning control law for a class of nonlinear switched systems with state delays and arbitrary switched rules, which perform a given task repeatedly. The stability condition for the proposed highorder learning control law is first established, and then the stability is analyzed based on contraction mapping approach in the sense of $\lambda$ norm. It is shown that the proposed iterative learning control law can guarantee the asymptotic convergence of the tracking error for the entire time interval through the iterative learning process. Two examples are given to illustrate the effectiveness of the proposed approach.
\end{abstract}

\section{Introduction}

A switched system is a hybrid dynamical system, which consists of a family of continuous-time or discrete-time subsystems and a rule that orchestrates the switching between them. During the past decades, switched systems have been widely studied, and many interesting results have been reported in the literature, for instance [1-3] and the references therein. The motivation to study switched systems is mainly in twofold. First of all, many engineering systems can be represented by switched systems, such as networked control systems (NCS) [4, 5], traffic control [6], automotive engine control, and aircraft control [7]. Secondly, the idea of controller switching is introduced in order to overcome the shortcomings of the single controller and improve system performance $[8,9]$. Some methods have been used in the study of switched systems such as the multiple Lyapunov functions [10,11], the concept of average dwell time [12], and piecewise quadratic Lyapunov functions [13].

Recent researches in switched system typically focus on the analysis of dynamic behaviors, such as stability [14], controllability, reachability $[15,16]$, and observability [17] aiming to design controllers with guaranteed stability and performance $[18,19]$. Besides the aforementioned problem, designing a controller to achieve tracking for switched systems is a challenging problem [20-22]. In [20], the tracking control problem for switched linear systems with timevarying delays is investigated, and the average dwell time approach and piecewise Lyapunov functional methods are utilized to the stability analysis and controller design. In [21], an observer-based tracking control approach is proposed for switched linear time-varying delay systems with unavailable states. The single Lyapunov-Krasovskii functional method is utilized to the stability analysis and controller design. In [22], the tracking control problem for switched nonlinear systems subject to an output constraint is considered. It is worth pointing out that most of these approaches are given based on the accurate model of nonlinear switched systems, and thus their control performances depend on the accuracy of the models. In addition, various unmodelled dynamics and uncertainties always exist in practical systems. The abovementioned model-based control approaches for switched systems may lead to bad performance or cause closed-loop system unstable in practice. Therefore, it is necessary and practical to design tracking control methods for switched systems requiring less knowledge about the system dynamics. 
Fortunately, for repetitive systems, iterative learning control (ILC) offers a systematic design that can improve the tracking performance by iterations in a fixed time interval. The key feature of this technique is to use information from the previous operation in order to enable the controlled system to perform better progressively from operation to operation. It seems that the main advantage of the iterative learning control strategy is to require less a priori knowledge about the system dynamics and less computational effort than many other types of control strategies. Hence, iterative learning control for repetitive dynamical systems has received considerable attention, and it has made significant progresses over the past two decades (see [23-30] and references therein). However, to the best of our knowledge, no one has been studied the iterative learning control for switched systems. This observation motivates the present study.

In practice, some switched systems are in general repeated, such as traffic system and batch process with multiprocedure. The traffic system can be viewed as a switched system [6]. We may easily find that traffic flow patterns in two consecutive days, or the same weekday of two consecutive weeks, are very close. Ruling out the occasional occurrence of accidents, the routine traffic flow on freeway in the macroscopic level will show inherent repeatability every day. Likely we can find the similarities on a monthly basis, or even a yearly basis [26]. For the batch process with multiprocedure, the system can also be considered as a switched system, and the different procedures represent the different subsystems. If the product is batch processing, then the switched system is operated repetitively. In this paper, the problem of iterative learning control for a class of nonlinear switched systems with arbitrary switched rules is considered. Despite much progress, significant research remains to be done in the direction of linear switched systems, especially since the majority of practical switched systems exhibit inherently nonlinear dynamics and delays [31-33]. Hence, we are focusing on ILC for nonlinear switched systems with time delay.

Most of the existing ILC schemes are based on the firstorder updating laws; that is, only the information of one previous iteration is employed. [34] used a high-order ILC law for tracking control of nonlinear systems, where, to form the control in current iteration, the information of several previous learning iterations, including control functions, tracking errors as well as their derivatives, is used. It is demonstrated that high-order ILC schemes have potential to give a better convergence performance than the first-order ILC schemes. Therefore, it is beneficial to investigate highorder ILC schemes for the tracking control of nonlinear switched systems.

The rest of this paper is organized as follows. In Section 2, the problem formulation is described. In Section 3, a sufficient condition which guarantees the stability of highorder PID-type ILC for the nonlinear switched ILC system is given. In Section 4, two examples are presented to validate the theoretical results. Finally, some conclusions are given in Section 5 .

\section{Problem Formulation}

Consider a nonlinear switched system with time delay, which performs a given task repeatedly, as follows:

$$
\begin{aligned}
\dot{x}_{k}(t)= & f_{\sigma(t)}\left(x_{k}(t), x_{d}(t-h), t\right) \\
& +B_{\sigma(t)}\left(x_{k}(t), x_{k}(t-d), t\right) u(t), \\
y_{k}(t)= & g_{\sigma(t)}\left(x_{k}(t), t\right),
\end{aligned}
$$

where $k$ denotes the $k$ th repetitive operation of the system. $x_{k}(t) \in R^{n}$ is the state vector, $u_{k}(t) \in R^{p}$ is the input vector, and $y_{k}(t) \in R^{m}$ is the output vector. $t \in[0, T]$ is the finite time interval, and $h, d<T$ are known time delay. $\sigma(t)$ : $\{1,2, \ldots\} \rightarrow \Psi=\{1,2, \ldots m\}$ is a switching signal, that is, a piecewise constant function. $m$ is the number of models (called subsystems) of the switched system. The vector nonlinear function $f_{\sigma(t)}(\cdot), g_{\sigma(t)}(\cdot)$, and matrix function $B_{\sigma(t)}(\cdot)$ have appropriate dimensions. In this paper, we assume $\sigma(t)$ is an arbitrary switched rule on the time domain, and it is invariable on the iteration domain, that means the functions $\left(f_{\sigma(t)}, g_{\sigma(t)}\right.$, and $\left.B_{\sigma(t)}\right)$ are allowed to take values, at an arbitrary discrete time, in the finite set

$$
\left\{\left(f_{1}, g_{1}, B_{1}\right), \ldots,\left(f_{m}, g_{m}, B_{m}\right)\right\} .
$$

In this case, the nonlinear switched system (1) can be described as

$$
\begin{aligned}
\dot{x}_{k}(t)= & f_{i}\left(x_{k}(t), x_{k}(t-h), t\right) \\
& +B_{i}\left(x_{k}(t), x_{k}(t-d), t\right) u_{k}(t), \\
y_{k}(t)= & g_{i}\left(x_{k}(t), t\right), \quad i \in\{1,2, \ldots, m\} .
\end{aligned}
$$

Basic assumptions for the nonlinear switched system are given as follows.

Assumption 1. For a desired trajectory $y_{d}(t)$, it exists $u_{d}(t)$ and $x_{d}(t)$ satisfying

$$
\begin{aligned}
\dot{x}_{d}(t)= & f_{i}\left(x_{d}(t), x_{d}(t-h), t\right) \\
& +B_{i}\left(x_{d}(t), x_{d}(t-d), t\right) u_{d}(t), \\
& y_{d}(t)=g_{i}\left(x_{d}(t), t\right),
\end{aligned}
$$

where $u_{d}(t)$ is the desired input and $x_{d}(t)$ is the desired state.

Assumption 2. The nonlinear function $f_{i}, B_{i}, g_{i}, g_{i x}=\partial g_{i} / \partial x$, $g_{i t}=\partial g_{i} / \partial t, i \in\{1,2, \ldots, m\}$ is uniformly globally Lipschitz in $x(t)$ on interval $[0, T]$, that is, for all $t \in[0, T], \exists$ constants $k_{h}, k_{f}, k_{B}$ such that

$$
\begin{aligned}
& \left\|h\left(x_{1}(t), t\right)-h\left(x_{2}(t), t\right)\right\| \leq k_{h}\left\|x_{1}(t)-x_{2}(t)\right\|, \\
& \left\|f_{i}\left(x_{1}(t), x_{1}(t-h), t\right)-f_{i}\left(x_{2}(t), x_{2}(t-h), t\right)\right\| \\
& \quad \leq k_{f}\left(\left\|x_{1}(t)-x_{2}(t)\right\|+\left\|x_{1}(t-h)-x_{2}(t-h)\right\|\right), \\
& \left\|B_{i}\left(x_{1}(t), x_{1}(t-d), t\right)-B_{i}\left(x_{2}(t), x_{2}(t-d), t\right)\right\| \\
& \quad \leq k_{B}\left(\left\|x_{1}(t)-x_{2}(t)\right\|+\left\|x_{1}(t-d)-x_{2}(t-d)\right\|\right),
\end{aligned}
$$

for any pair $\left(x_{1}(t), x_{2}(t)\right)$, where $h \in\left\{g_{i}, g_{i x}, g_{i t}\right\}$. 
Assumption 3. The resetting condition is satisfied for all the iteration; that is,

$$
x_{k}(t)=x_{d}(t), \quad t \in[-\mu, 0] \text {, }
$$

where $\mu=\max \{h, d\}$ and $x_{d}(t)$ is the desired initial function.

Remark 4. From Assumption 1, since $u_{d}(t)$ exists uniquely, the uniform convergence of the control profile $u(t)$ to $u_{d}(t)$ implies that the state and output tracking errors will vanish. Assumption 2 is a basic condition for switched systems which means that system states are continuous, even for structure switches.

Remark 5. Assumption 3 means $x_{k}(0)=x_{d}(0)$ for all $k$, which is the identical initial condition for ILC system. For a switched system, even though the dynamic behavior is changing between different subsystems, the initial condition reset is often satisfied in many practical systems. For instance, when a product is processed by several different procedures, then the system can be considered as a switched system, and the different procedures represent the different subsystems. If the product is batch processing, then the switched system is operated repetitively. Even though the processing is changing between different procedures, the initial state of the product is identical.

Remark 6. The switched rule $\sigma(t)$ in system (1) is an arbitrary switched rule on the time domain, and it is invariable on the iteration domain. One may argue that the problem considered in this paper is similar to the ILC for time varying nonlinear system. However, there are some crucial differences. The time varying system admits a family of solutions that can be parameterized solely by the initial condition, whereas the switched system admits a family of solutions that is parameterized both by the initial condition and the switching signal. Besides, the switched system has sudden transient at some time instants.

The control target is to find a control input sequence $u_{k}(t)=u_{d}(t)$, such that $y_{k}(t)$ converges to $y_{d}(t)$ as $k \rightarrow \infty$; that is, as the learning iteration repeats, the system output converges to the desired trajectory.

Now, the following high-order ILC updating law for the system (3) is proposed which uses the $P, I$, and $D$ information of tracking errors:

$$
\begin{aligned}
u_{k+1}(t) & \\
= & \sum_{j=1}^{N} P_{j} u_{k-j+1}(t) \\
& +\sum_{j=1}^{N}\left\{Q_{j} e_{k-j+1}(t)+R_{j} \dot{e}_{k-j+1}(t)+S_{j} \int_{0}^{t} e_{k-j+1}(t) d t\right\},
\end{aligned}
$$

where $e_{k}(t)=y_{d}(t)-y_{k}(t)$ is the tracking error, integer $N \geq 1$ is the order of the ILC law. $P_{j}, Q_{j}, R_{j}$, and $S_{j}$ are learning gain matrices. The learning operators $Q_{j}, R_{j}$, and $S_{j}$ are chosen to be bounded, and their upper bounds denoted by $b_{\mathrm{Q}}, b_{R}$, and $b_{S}$, respectively, are defined by

$$
b_{Q}=\max _{1 \leq j \leq N}\left\|Q_{j}\right\|, \quad b_{R}=\max _{1 \leq j \leq N}\left\|R_{j}\right\|, \quad b_{S}=\max _{1 \leq j \leq N}\left\|S_{j}\right\| .
$$

As usual, it is assumed that $u_{k}(t)=0$ and $e_{k}(t)=0$ for $k<0$.

The $\lambda$-norm will be used in this paper. It is defined by

$$
\|f(\cdot)\|_{\lambda}=\sup _{0 \leq t \leq T}\left\{\mathrm{e}^{-\lambda t}\|f(t)\|\right\}, \quad \lambda>0,
$$

for a vector function $f:[0, T] \rightarrow R^{n}$.

For the sake of brevity, the following notations will be used:

$$
\begin{aligned}
& h_{k}=h\left(x_{k}(t), t\right), \quad h_{d}=h\left(x_{d}(t), t\right), \\
& \delta h_{k}=h_{d}-h_{k}, \quad b_{h}=\sup \|h(x(t), t)\|,
\end{aligned}
$$

where $h$ represents a function concerned. The partial derivatives of $h(x(t), t)$ are denoted by

$$
\begin{array}{ll}
h_{x k}=\left.\frac{\partial h(x, t)}{\partial x}\right|_{x=x_{k}(t)}, & h_{t k}=\left.\frac{\partial h(x, t)}{\partial t}\right|_{x=x_{k}(t)}, \\
h_{x d}=\left.\frac{\partial h(x, t)}{\partial x}\right|_{x=x_{d}(t)}, & h_{t d}=\left.\frac{\partial h(x, t)}{\partial t}\right|_{x=x_{d}(t)} .
\end{array}
$$

Let $k_{h}$ be the Lipschitz constant of the function $h$ with respect to $x$ in $[0, T]$. Then it is easy to see that

$$
\left\|\delta h_{k}\right\| \leq k_{h}\left\|\delta x_{k}\right\| \text {. }
$$

\section{Main Result}

Note that the $\sigma(t)$ is an arbitrary switching rule during the finite time interval $[0, T]$, which is different from the aforementioned studies [14-19]. The switching rule $\sigma(t)$ can be described as

$$
\sigma=\left(i_{0}, t_{0}\right),\left(i_{1}, t_{1}\right),\left(i_{2}, t_{2}\right), \ldots,\left(i_{n}, t_{n}\right),
$$

where $t_{0}$ is the initial time instant, by default $t_{0}=0 . t_{n}$ is the terminal time instant with $t_{n}=T . t_{1}, t_{2}, \cdots, t_{n}$ denote the switching instants, and the pair $\left(i_{n}, t_{n}\right)$ which represents subsystem $i_{n}$ is active during the interval $t_{n-1} \leq t \leq t_{n}$. $t_{n}-t_{n-1}$ is the dwell time of the subsystem $i_{n}$. Clearly, the control input of overall systems is a piecewise function, and the discontinuity points are those switching instants.

Without loss of generality, we can assume that the arbitrary switching rule $\sigma(t)$ is given as

$$
\sigma(t)=i= \begin{cases}1, & t \in\left[0, t_{1}\right], \\ 2, & t \in\left[t_{1}, t_{2}\right], \\ \vdots & \\ m, & t \in\left[t_{m-1}, T\right] .\end{cases}
$$

Switched sequence (14) implies each subsystem only operated once during the whole interval $[0, T]$.

To proof the main result, we first give the following lemmas. 
Lemma 7. Suppose that a real positive series $\left\{a_{n}\right\}_{1}^{\infty}$ satisfies

$$
\begin{array}{r}
a_{n} \leq \rho_{1} a_{n-1}+\rho_{2} a_{n-2}+\cdots+\rho_{N} a_{n-N}+\varepsilon, \\
(n=N+1, N+2, \ldots),
\end{array}
$$

where $\rho_{i} \geq 0(i=1,2, \ldots, N), \varepsilon \geq 0$ and

$$
\rho=\sum_{i=1}^{N} \rho_{i}<1
$$

Then the following holds:

$$
\lim _{n \rightarrow \infty} a_{n} \leq \frac{\varepsilon}{1-\rho}
$$

Proof. Let $n_{1} \in\{n-1, n-2, \ldots, n-N\}$ be an index number such that $a_{n_{1}}=\max \left\{a_{n-1}, a_{n-2}, \ldots, a_{n-N}\right\}$. Then, from (15), we have

$$
\begin{aligned}
a_{n} & \leq \rho_{1} a_{n-1}+\rho_{2} a_{n-2}+\cdots+\rho_{N} a_{n-N}+\varepsilon, \\
& \leq \rho a_{n_{1}}+\varepsilon .
\end{aligned}
$$

Similarly, let $n_{2} \in\left\{n_{1}-1, n_{1}-2, \ldots, n_{1}-N\right\}$ such that

$$
a_{n_{2}}=\max \left\{a_{n_{1}-1}, a_{n_{1}-2}, \ldots, a_{n_{1}-N}\right\} \text {. }
$$

Then

$$
\begin{aligned}
a_{n_{1}} & \leq \rho_{1} a_{n_{1}-1}+\rho_{2} a_{n_{1}-2}+\cdots+\rho_{N} a_{n_{1}-N}+\varepsilon \\
& \leq \rho a_{n_{2}}+\varepsilon .
\end{aligned}
$$

Therefore

$$
a_{n} \leq \rho^{2} a_{n_{2}}+\rho \varepsilon+\varepsilon
$$

In general,

$$
a_{n} \leq \rho^{m} a_{n_{m}}+\rho^{m-1} \varepsilon+\rho^{m-2} \varepsilon+\cdots+\rho \varepsilon+\varepsilon,
$$

where $m$ and $n_{m}$ are positive integers. If $m$ is chosen such that $n_{m} \leq N$, then $(n / N)-1 \leq m \leq n-N$, and therefore $m \rightarrow \infty$ when $n \rightarrow \infty$. Let $M=\max \left\{a_{1}, a_{2}, \ldots, a_{N}\right\}$, and then

$$
a_{n} \leq \rho^{m} M+\frac{1-\rho^{m}}{1-\rho} \varepsilon
$$

which implies

$$
\lim _{n \rightarrow \infty} a_{n} \leq \frac{\varepsilon}{1-\rho}
$$

This completes the proof of Lemma 7.

Lemma 8 ((Bellman-Gronwall lemma) [35]). Assume that functions $\varepsilon(t), c(t), a(t): R^{n} \times[0, T] \rightarrow R^{n}$ are continuous and nonnegative function in $t$. If the following holds:

$$
\varepsilon(t) \leq c(t)+\int_{0}^{t} a(\tau) \varepsilon(\tau) d \tau, \quad t \in[0, T],
$$

then

$$
\varepsilon(t) \leq c(t) e^{\int_{0}^{t} a(\tau) d \tau}, \quad t \in[0, T] .
$$

Now, we can give the following result.

Theorem 9. Consider the nonlinear switched system (3) with switching rule (14), and Assumptions 1-3 are satisfied. If

$$
\sum_{j=1}^{N} P_{j}=I_{m}
$$

and there exist positive numbers $\rho_{j}$ satisfying

$$
\begin{gathered}
\left\|P_{j}-R_{j} g_{i x} B_{i}\right\| \leq \rho_{j}, \\
\sum_{j=1}^{N} \rho_{j}=\rho<1,
\end{gathered}
$$

then the system output converges to the desired output; that is, $y_{d}(t) \rightarrow y_{k}(t)$ is ensured as $k \rightarrow \infty$ for all $t \in[0, T]$.

Proof. Denote $l=k-j+1$, and the ILClaw (7) can be rewritten as

$$
u_{k+1}(t)=\sum_{j=1}^{N} P_{j} u_{l}(t)
$$

$$
+\sum_{j=1}^{N}\left\{Q_{j} e_{l}(t)+R_{j} \dot{e}_{l}(t)+S_{j} \int_{0}^{t} e_{l}(t) d t\right\} .
$$

From (3), we have

$$
\begin{aligned}
e_{l}(t) & =y_{d}(t)-y_{l}(t) \\
& =g_{i}\left(x_{d}(t), t\right)-g_{i}\left(x_{l}(t), t\right)=\delta g_{i, l},
\end{aligned}
$$

$$
\begin{aligned}
\dot{e}_{l}(t) & =\dot{y}_{d}(t)-\dot{y}_{l}(t) \\
& =g_{i, x d} \dot{x}_{d}+g_{i, t d}-g_{i, x l} \dot{x}_{l}-g_{i, t l} \\
& =\delta g_{i, x l} \dot{x}_{d}+g_{i, x l} \delta \dot{x}_{l}+\delta g_{i, t l},
\end{aligned}
$$

where $l=k, k-1, \ldots, k-N+1$, and

$$
\begin{gathered}
\dot{x}_{d}=f_{i, d}+B_{i, d} u_{d}, \\
\delta \dot{x}_{l}=f_{i, d}+B_{i, d} u_{d}-f_{i, l}-B_{i, l} u_{l} \\
=\delta f_{i, l}+\delta B_{i, l} u_{d}+B_{i, l} \delta u_{l},
\end{gathered}
$$

where

$$
\begin{aligned}
\delta f_{i, l} & =f_{i, d}-f_{i, l} \\
& =f_{i}\left(x_{d}(t), x_{d}(t-h), t\right)-f_{i}\left(x_{l}(t), x_{l}(t-h), t\right), \\
\delta B_{i, l} & =B_{i, d}-B_{i, l} \\
& =B_{i}\left(x_{d}(t), x_{d}(t-d), t\right)-B_{i}\left(x_{l}(t), x_{l}(t-d), t\right) .
\end{aligned}
$$


Now, by using ILC updating law (29) and condition (27), we have

$$
\begin{aligned}
\delta u_{k+1} & \\
= & u_{d}-u_{k+1} \\
= & \sum_{j=1}^{N} P_{j} \delta u_{l}-\sum_{j=1}^{N} Q_{j} \delta g_{i, l}-\sum_{j=1}^{N} S_{j} \int_{0}^{t} \delta g_{i, l} d \tau \\
& -\sum_{j=1}^{N} R_{j}\left\{\delta g_{i, x l} \dot{x}_{d}+g_{i, x l} \delta \dot{x}_{l}+\delta g_{i, t l}\right\} \\
= & \sum_{j=1}^{N} P_{j} \delta u_{l}-\sum_{j=1}^{N} Q_{j} \delta g_{i, l}-\sum_{j=1}^{N} S_{j} \int_{0}^{t} \delta g_{i, l} d \tau \\
& -\sum_{j=1}^{N} R_{j}\left\{\delta g_{i, x l} \dot{x}_{d}+\delta g_{i, t l}+g_{i, x l}\left(\delta f_{i, l}+\delta B_{i, l} u_{d}+B_{i, l} \delta u_{l}\right)\right\} \\
= & \sum_{j=1}^{N}\left[P_{j}-R_{j} g_{i, x l} B_{i, l}\right] \delta u_{l}-\sum_{j=1}^{N} Q_{j} \delta g_{i, l}-\sum_{j=1}^{N} S_{j} \int_{0}^{t} \delta g_{i, l} d \tau \\
& -\sum_{j=1}^{N} R_{j}\left\{\delta g_{i, x l} \dot{x}_{d}+\delta g_{i, t l}+g_{i, x l}\left(\delta f_{i, l}+\delta B_{i, l} u_{d}\right)\right\} .
\end{aligned}
$$

Taking norms yields

$$
\begin{aligned}
& \left\|\delta u_{k+1}\right\| \\
& \leq \sum_{j=1}^{N} \rho_{j}\left\|\delta u_{l}\right\|+\sum_{j=1}^{N} b_{Q} k_{g}\left\|\delta x_{l}\right\|+\sum_{j=1}^{N} b_{S} \int_{0}^{t} k_{g}\left\|\delta x_{l}\right\| d \tau \\
& +\sum_{j=1}^{N} b_{R}\left\{k_{g x} b_{x_{d}}\left\|\delta x_{l}\right\|+k_{g t}\left\|\delta x_{l}\right\|\right. \\
& +b_{g x}\left(\left(k_{f}+b_{u_{d}} k_{B}\right)\left\|\delta x_{l}\right\|\right. \\
& +k_{f}\left\|\delta x_{l}(t-h)\right\| \\
& \left.\left.+b_{u_{d}} k_{B}\left\|\delta x_{l}(t-d)\right\|\right)\right\} \\
& \leq \sum_{j=1}^{N} \rho_{j}\left\|\delta u_{l}\right\|+a_{0} \sum_{j=1}^{N}\left\|\delta x_{l}\right\|+a_{1} \sum_{j=1}^{N} \int_{0}^{t}\left\|\delta x_{l}\right\| d \tau \\
& +b_{R} \sum_{j=1}^{N}\left\{b_{g x} k_{f}\left\|\delta x_{l}(t-h)\right\|+b_{g x} b_{u_{d}} k_{B}\left\|\delta x_{l}(t-d)\right\|\right\}
\end{aligned}
$$

where

$$
\begin{gathered}
a_{0}=b_{\mathrm{Q}} k_{g}+b_{R}\left[k_{g x} b_{x_{d}}+k_{g t}+b_{g x}\left(k_{f}+b_{u_{d}} k_{B}\right)\right], \\
a_{1}=b_{S} k_{g} .
\end{gathered}
$$

Denoting $\theta \in\{h, d\}$, from Assumption 3, we have

$$
\begin{aligned}
& \int_{0}^{t}\left\|\delta x_{k}(\tau-\theta)\right\| d \tau \\
& \quad=\int_{-\theta}^{0}\left\|x_{d}(\tau)-x_{k}(\tau)\right\| d \tau+\int_{0}^{t-\theta}\left\|x_{d}(\tau)-x_{k}(\tau)\right\| d \tau \\
& \quad=\int_{0}^{t-\theta}\left\|\delta x_{k}(\tau)\right\| d \tau \leq \int_{0}^{t}\left\|\delta x_{k}(\tau)\right\| d \tau,
\end{aligned}
$$

which implies $\left\|\delta x_{l}(t-\theta)\right\| \leq\left\|\delta x_{l}(t)\right\|$.

Performing the $\lambda$-norm operation for (34) and considering $\left\|\delta x_{l}(t-\theta)\right\| \leq\left\|\delta x_{l}(t)\right\|$, we can obtain

$$
\left\|\delta u_{k+1}\right\|_{\lambda} \leq \sum_{j=1}^{N} \rho_{j}\left\|\delta u_{l}\right\|_{\lambda}+a_{2} \sum_{j=1}^{N}\left\|\delta x_{l}\right\|_{\lambda}
$$

where $a_{2}=a_{0}+a_{1}+b_{R} b_{g x}\left(k_{f}+b_{u_{d}} k_{B}\right)$.

(1) When $t \in\left[0, t_{1}\right]$. In this case, the subsystem 1 is active. From (3) and Assumption 1, we can obtain

$$
\begin{aligned}
\delta x_{l} & =\delta x_{l}(0)+\int_{0}^{t} \delta \dot{x}_{l} d \tau \\
& =\delta x_{l}(0)+\int_{0}^{t}\left(\delta f_{1, l}+\delta B_{1, l} u_{d}+B_{1, l} \delta u_{l}\right) d \tau .
\end{aligned}
$$

Taking norms yields

$$
\begin{aligned}
\left\|\delta x_{l}\right\| & =\left\|\delta x_{l}(0)+\int_{0}^{t} \delta \dot{x}_{l} d \tau\right\| \\
\leq & \left\|\delta x_{l}(0)\right\| \\
& +\int_{0}^{t}\left(\left(k_{f}+b_{u_{d}} k_{B}\right)\left\|\delta x_{l}\right\|+k_{f}\left\|\delta x_{l}(\tau-h)\right\|\right) d \tau \\
& +\int_{0}^{t}\left(b_{u_{d}} k_{B}\left\|\delta x_{l}(\tau-d)\right\|+b_{B}\left\|\delta u_{l}\right\|\right) d \tau .
\end{aligned}
$$

Since $x_{k}(0)=x_{d}(0)$, then $\delta x_{l}(0)=0$. From (36) and (39), we have

$$
\left\|\delta x_{l}\right\| \leq \int_{0}^{t}\left(\left(k_{f}+b_{u_{d}} k_{B}+k_{f}+b_{u_{d}} k_{B}\right)\left\|\delta x_{l}\right\|+b_{B}\left\|\delta u_{l}\right\|\right) d \tau .
$$

Defining $a_{3}=k_{f}+b_{u_{d}} k_{B}+k_{f}+b_{u_{d}} k_{B}$, using Lemma 8 for (40), we have

$$
\left\|\delta x_{l}\right\| \leq \int_{0}^{t} e^{a_{3}(t-\tau)} b_{B}\left\|\delta u_{l}\right\| d \tau, \quad t \in\left[0, t_{1}\right] .
$$


Taking $\lambda$-norm yields

$$
\left\|\delta x_{l}\right\|_{\lambda} \leq \frac{b_{B} O_{1}\left(\lambda^{-1}\right)}{1-a_{3} O_{1}\left(\lambda^{-1}\right)}\left\|\delta u_{l}\right\|_{\lambda}
$$

where $O_{1}\left(\lambda^{-1}\right)=\left(1-e^{-\lambda t_{1}}\right) / \lambda$. Combing (37) and (42) yields

$$
\begin{aligned}
\left\|\delta u_{k+1}\right\|_{\lambda} & \leq \sum_{j=1}^{N} \rho_{j}\left\|\delta u_{l}\right\|_{\lambda}+\frac{a_{2} b_{B} O_{1}\left(\lambda^{-1}\right)}{1-a_{3} O_{1}\left(\lambda^{-1}\right)} \sum_{j=1}^{N}\left\|\delta u_{l}\right\|_{\lambda}, \\
& =\sum_{j=1}^{N} \bar{\rho}_{j}\left\|\delta u_{l}\right\|_{\lambda},
\end{aligned}
$$

where

$$
\bar{\rho}_{j}=\rho_{j}+\frac{a_{2} b_{B} O_{1}\left(\lambda^{-1}\right)}{1-a_{3} O_{1}\left(\lambda^{-1}\right)} .
$$

By condition (28) in Theorem 9, one can find a sufficiently large $\lambda$ such that $\bar{\rho}_{j}<1$ and $\sum_{j=1}^{N} \bar{\rho}_{j}=\bar{\rho}<1$. Then, according to Lemma 7 , it can be concluded that

$$
\lim _{k \rightarrow \infty}\left\|\delta u_{k}\right\|_{\lambda}=0, \quad t \in\left[0, t_{1}\right] .
$$

From (42) and $\left\|e_{k}\right\|_{\lambda} \leq k_{g}\left\|\delta x_{k}\right\|_{\lambda}$, we can observe that the tracking errors $\left\|e_{k}\right\|_{\lambda}$ and $\left\|\delta x_{k}\right\|_{\lambda}$ both tend to zero for $t \in$ $\left[0, t_{1}\right]$ when $k \rightarrow \infty$.

(2) When $t \in\left[t_{1}, t_{2}\right]$. In this case, the subsystem 2 is active. The state error has the following expression:

$$
\begin{aligned}
\delta x_{l} & =\delta x_{l}\left(t_{1}\right)+\int_{t_{1}}^{t} \delta \dot{x}_{l} d \tau \\
& =\delta x_{l}\left(t_{1}\right)+\int_{t_{1}}^{t}\left(\delta f_{2, l}+\delta B_{2, l} u_{d}+B_{2, l} \delta u_{l}\right) d \tau .
\end{aligned}
$$

Taking norms yields

$$
\begin{aligned}
\left\|\delta x_{l}\right\|= & \left\|\delta x_{l}\left(t_{1}\right)+\int_{t_{1}}^{t} \delta \dot{x}_{l} d \tau\right\| \\
\leq & \left\|\delta x_{l}\left(t_{1}\right)\right\| \\
& +\int_{t_{1}}^{t}\left(\left(k_{f}+b_{u_{d}} k_{B}\right)\left\|\delta x_{l}\right\|+k_{f}\left\|\delta x_{l}(t-h)\right\|\right) d \tau \\
& +\int_{t_{1}}^{t}\left(b_{u_{d}} k_{B}\left\|\delta x_{l}(t-d)\right\|+b_{B}\left\|\delta u_{l}\right\|\right) d \tau .
\end{aligned}
$$

Due to the fact that $\left\|\delta x_{l}(t-h)\right\| \leq\left\|\delta x_{l}(t)\right\|,\left\|\delta x_{l}(t-d)\right\| \leq$ $\left\|\delta x_{l}(t)\right\|$, we have

$$
\begin{aligned}
\left\|\delta x_{l}\right\| \leq & \left\|\delta x_{l}\left(t_{1}\right)\right\| \\
& +\int_{t_{1}}^{t}\left(a_{3}\left\|\delta x_{l}\right\|+b_{B}\left\|\delta u_{l}\right\|\right) d \tau, \quad t \in\left[t_{1}, t_{2}\right] .
\end{aligned}
$$

Using Lemma 8 for (40) and taking $\lambda$-norm yield

$$
\left\|\delta x_{l}\right\|_{\lambda} \leq\left\|\delta x_{l}\left(t_{1}\right)\right\|+\frac{b_{B} O_{2}\left(\lambda^{-1}\right)}{1-a_{3} O_{2}\left(\lambda^{-1}\right)}\left\|\delta u_{l}\right\|_{\lambda},
$$

where $\mathrm{O}_{2}\left(\lambda^{-1}\right)=\left(1-e^{-\lambda t_{2}}\right) / \lambda$. Combing (37) and (49) yields

$$
\begin{aligned}
\left\|\delta u_{k+1}\right\|_{\lambda} \leq & \sum_{j=1}^{N} \rho_{j}\left\|\delta u_{l}\right\|_{\lambda}+a_{2} \sum_{j=1}^{N}\left\|\delta x_{l}\left(t_{1}\right)\right\|_{\lambda} \\
& +\frac{a_{2} b_{B} O_{2}\left(\lambda^{-1}\right)}{1-a_{3} O_{2}\left(\lambda^{-1}\right)} \sum_{j=1}^{N}\left\|\delta u_{l}\right\|_{\lambda} \\
= & \sum_{j=1}^{N} \overline{\bar{\rho}}_{j}\left\|\delta u_{l}\right\|_{\lambda}+a_{2} \sum_{j=1}^{N}\left\|\delta x_{l}\left(t_{1}\right)\right\|_{\lambda},
\end{aligned}
$$

where

$$
\overline{\bar{\rho}}_{j}=\rho_{j}+\frac{a_{2} b_{B} O_{2}\left(\lambda^{-1}\right)}{1-a_{3} O_{2}\left(\lambda^{-1}\right)} .
$$

By condition (28) in Theorem 9, one can find a sufficiently large $\lambda$ such that $\overline{\bar{\rho}}_{j}<1$ and $\sum_{j=1}^{N} \overline{\bar{\rho}}_{j}=\overline{\bar{\rho}}<1$.

Note that (50) can be rewritten as

$$
\left\|\delta u_{k}\right\|_{\lambda} \leq \sum_{j=1}^{N} \overline{\bar{\rho}}_{j}\left\|\delta u_{k-j}\right\|_{\lambda}+\xi_{k}
$$

where $\xi_{k}=a_{2} \sum_{j=1}^{N}\left\|\delta x_{k-j}\left(t_{1}\right)\right\|_{\lambda}$.

Let $k_{1} \in\{k-1, \ldots, k-N\}$ be an iteration number such that

$$
u_{k_{1}}=\max \left\{u_{k-1}, u_{k-2}, \ldots, u_{k-N}\right\} .
$$

Then, from (50), it is easy to see that

$$
\left\|\delta u_{k}\right\|_{\lambda} \leq \overline{\bar{\rho}}\left\|\delta u_{k_{1}}\right\|_{\lambda}+\xi_{k} .
$$

Similarly, let $k_{2} \in\left\{k_{1}-1, k_{1}-2, \ldots, k_{1}-N\right\}$ such that

$$
u_{k_{2}}=\max \left\{u_{k_{1}-1}, u_{k_{1}-2}, \ldots, u_{k_{1}-N}\right\} \text {. }
$$

then

$$
\left\|\delta u_{k_{1}}\right\|_{\lambda} \leq \sum_{j=1}^{N} \overline{\bar{\rho}}_{j}\left\|\delta u_{k_{1}-j}\right\|_{\lambda}+\xi_{k_{1}} \leq \overline{\bar{\rho}}\left\|\delta u_{k_{2}}\right\|_{\lambda}+\xi_{k_{1}},
$$

therefore

$$
\left\|\delta u_{k}\right\|_{\lambda} \leq \overline{\bar{\rho}}^{2}\left\|\delta u_{k_{2}}\right\|_{\lambda}+\overline{\bar{\rho}} \xi_{k_{1}}+\xi_{k}
$$

In general,

$$
\begin{aligned}
\left\|\delta u_{k}\right\|_{\lambda} \leq & \overline{\bar{\rho}}^{m^{\prime}}\left\|\delta u_{k_{m}}\right\|_{\lambda} \\
& +\overline{\bar{\rho}}^{m^{\prime}-1} \xi_{k_{m^{\prime}-1}}+\overline{\bar{\rho}}^{m^{\prime}-2} \xi_{k_{m^{\prime}-2}} \\
& +\cdots+\overline{\bar{\rho}} \xi_{k_{1}}+\xi_{k},
\end{aligned}
$$


where $m^{\prime}$ and $k_{m^{\prime}}$ are positive integers. If $m^{\prime}$ is chosen such that $k_{m^{\prime}} \leq N$, then

$$
\frac{k}{N}-1 \leq m^{\prime} \leq k-N
$$

therefore $m^{\prime} \rightarrow \infty$ when $k \rightarrow \infty$. Let $M=\max \left\{\delta u_{1}\right.$, $\left.\delta u_{2}, \ldots, \delta u_{N}\right\}$, then

$$
\left\|\delta u_{k}\right\|_{\lambda} \leq \overline{\bar{\rho}}^{m^{\prime}} M+\sum_{j=0}^{m^{\prime}-1} \overline{\bar{\rho}}^{j} \xi_{k_{j}}
$$

where $\xi_{k_{0}}=\xi_{k}$. Note that $k \rightarrow \infty$ means $m^{\prime} \rightarrow \infty$, $k_{j} \rightarrow \infty, j \in\left\{0,1,2, \ldots, m^{\prime}\right\}$. From (45), we know that $\lim _{k \rightarrow \infty}\left\|\delta x_{k}\left(t_{1}\right)\right\|_{\lambda}=0$, it also means $\lim _{k \rightarrow \infty} \xi_{k_{j}}=0$. Taking $k \rightarrow \infty$ for (60) gives

$$
\lim _{k \rightarrow \infty}\left\|\delta u_{k}\right\|_{\lambda} \leq M \lim _{k \rightarrow \infty} \overline{\bar{\rho}}^{m^{\prime}}+\lim _{k \rightarrow \infty} \sum_{j=0}^{m^{\prime}-1} \overline{\bar{\rho}}^{j} \xi_{k_{j}} .
$$

Considering $\lim _{k \rightarrow \infty} \overline{\bar{\rho}}^{m^{\prime}}=0$ and $\lim _{k \rightarrow \infty} \sum_{j=0}^{m^{\prime}-1} \overline{\bar{\rho}}^{j} \xi_{k_{j}}=0$, (61) implies

$$
\lim _{k \rightarrow \infty}\left\|\delta u_{k}\right\|_{\lambda}=0
$$

From (49) and $\left\|e_{k}\right\|_{\lambda} \leq k_{g}\left\|\delta x_{k}\right\|_{\lambda}$, we can also observe that the tracking errors $\left\|e_{k}\right\|_{\lambda}$ and $\left\|\delta x_{k}\right\|_{\lambda}$ both tend to zero for $t \in$ $\left[t_{1}, t_{2}\right]$ when $k \rightarrow \infty$.

In this analogy, $\lim _{k \rightarrow \infty}\left\|e_{k}\right\|_{\lambda}=0, \lim _{k \rightarrow \infty}\left\|\delta x_{k}\right\|_{\lambda}=$ 0 , and $\lim _{k \rightarrow \infty}\left\|\delta u_{k}\right\|_{\lambda}=0$ can also be obtained for $t \in$ $\left[t_{2}, t_{3}\right], t \in\left[t_{3}, t_{4}\right], \ldots,\left[t_{m-1}, T\right]$. Hence, for the whole time interval $t \in[0, T]$, we have $\lim _{k \rightarrow \infty}\left[y_{d}(t)-y_{k}(t)\right]=0$.

This completes the proof.

Remark 10. Theorem 9 is given for the nonlinear switched system with the switched sequence (14), which assumes each subsystem only operated once during the whole interval $[0, T]$, and the active sequence for subsystems is $\{1,2, \ldots, m\}$. From the proof process of Theorem 9, we know that the result can also be extended to the arbitrary switch sequence with more times active for each subsystem.

Remark 11. High-order ILC updating law utilizes the past experiences comprehensively and has more flexibilities in choosing learning operators and parameters. Hence, the better ILC performance can be expected. If the system dynamics is totally unknown, like the selection of learning parameters in traditional ILC laws, the order $N$ selection is also based on a trial-and-error method, which should be also in an iterative learning way. In practice, $N$ should normally be chosen to be less than or equal to 3 .
Remark 12. In many practical systems, stochastic disturbances are unavoidable [36-38]. In this case, the nonlinear switched system (1) can be described by

$$
\begin{aligned}
\dot{x}_{k}(t)= & f_{\sigma(t)}\left(x_{k}(t), x_{d}(t-h), t\right) \\
& +B_{\sigma(t)}\left(x_{k}(t), x_{k}(t-d), t\right) u(t)+w_{k}(t), \\
& y_{k}(t)=g_{\sigma(t)}\left(x_{k}(t), t\right)+v_{k}(t),
\end{aligned}
$$

where $w_{k}(t) \in R^{n}$ and $v_{k}(t) \in R^{m}$ are state disturbances and output disturbances, respectively. If the disturbances are bounded in the sense of $\left\|w_{k}(t)\right\| \leq b_{w}$ and $\left\|v_{k}(t)\right\| \leq b_{v}$ for all $k \geq 0$, where $b_{w}$, and $b_{v}$ are positive constants, from the proof of Theorem 9, it is easy obtained that, when the PID ILC law (7) is used for system (12), if the conditions in Theorem 9 are guaranteed, then the system output converges to the desired output with a bounded error. The error bound depends on the $b_{w}$ and $b_{v}$. The similar results can also be founded in ILC for general nonlinear systems with disturbances $[39,40]$.

\section{Simulation Illustrations}

In this simulation test, let us consider the following SISO nonlinear switched system with two subsystems:

$$
\begin{gathered}
S_{1}:\left\{\begin{aligned}
& {\left[\begin{array}{c}
\dot{x}_{1, k}(t) \\
\dot{x}_{2, k}(t)
\end{array}\right]=} {\left[\begin{array}{c}
0.8 \sin \left(x_{1, k}(t)\right) \\
0.3 e^{-t} \cos \left(x_{1, k}(t)\right)-0.4 \sin \left(x_{2, k}(t)\right)
\end{array}\right] } \\
&+\left[\begin{array}{l}
1 \\
0
\end{array}\right] u_{k}(t), \\
& y_{k}(t)=x_{1, k}(t)+0.5 x_{2, k}(t),
\end{aligned}\right. \\
S_{2}:\left\{\begin{array}{c}
{\left[\begin{array}{c}
\dot{x}_{1, k}(t) \\
\dot{x}_{2, k}(t)
\end{array}\right]=\left[\begin{array}{c}
-0.6 \sin \left(x_{1, k}(t)\right)+0.3 \sin \left(x_{2, k}(t)\right) \\
0.5 e^{-t} \sin \left(x_{2, k}(t)\right)
\end{array}\right]} \\
+\left[\begin{array}{l}
0.5 \\
0.7
\end{array}\right] u_{k}(t), \\
y_{k}(t)=0.2 x_{1, k}(t)+x_{2, k}(t) .
\end{array}\right.
\end{gathered}
$$

The nonlinear switched system is operated during the two subsystems with arbitrary switched law in time domain, and the desired output is given as $y_{d}(t)=\sin (30 t)+t e^{2 t}$, and $t \epsilon$ $[0,1]$. For the initial state, it is assumed that $x_{k}(0)=x_{d}(0)=0$ for all $k$. The ILC law (7) is applied by adopting the zero initial control input $u_{0}(t)=0$ for all $t \in[0,1]$. In simulation, we produces a random sequence $\sigma(t), t \in[0,1]$ with the value is 1 and 2, as shown in Figure 1. If $\sigma(t)=1$, the system (64) is $S_{1}$; otherwise, if $\sigma(t)=2$, the system (64) is $S_{2}$.

To check the tracking performance, we consider the following second-order ILC law

$$
\begin{aligned}
u_{k+1}(t)= & u_{k}(t)+Q_{1} e_{k-1}(t)+Q_{2} e_{k}(t) \\
& +R_{1} \dot{e}_{k-1}(t)+R_{2} \dot{e}_{k}(t),
\end{aligned}
$$




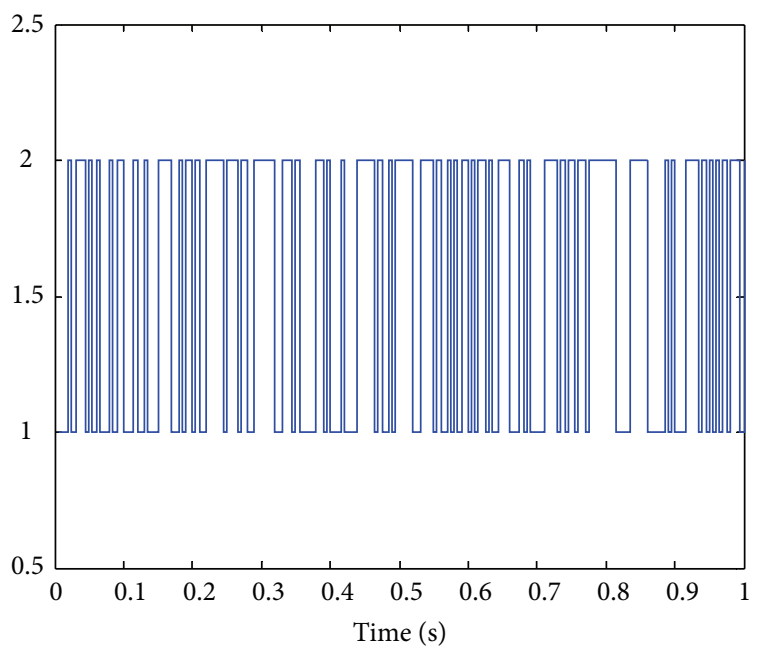

FIGURE 1: The random switched rule $\sigma(t)$ for system (64).

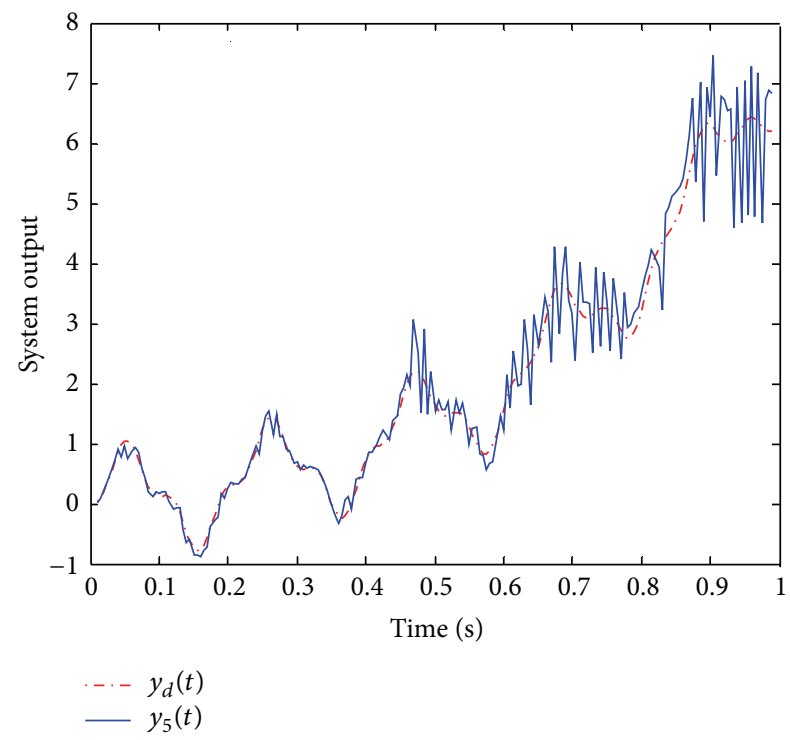

FIGURE 2: System output trajectory at 5th iteration for Example 1.

where $Q_{1}=0.3, Q_{2}=0.5, R_{1}=0.9$, and $R_{2}=1.2$. Note that the nonlinear functions $\sin (x), \cos (x)$ are both uniformly globally Lipschitz in $x$ and uniformly bounded for all $t \in[0,1]$ and $x \in R$. It is obvious that $g_{i x}$ and $B_{i}$ are also bounded. Checking the condition in Theorem 9, we have

$$
\begin{gathered}
g_{1 x} B_{1}=\left[\begin{array}{ll}
1 & 0.5
\end{array}\right]\left[\begin{array}{l}
1 \\
0
\end{array}\right]=1, \quad g_{2 x} B_{2}=\left[\begin{array}{ll}
0.2 & 1
\end{array}\right]\left[\begin{array}{l}
0.5 \\
0.7
\end{array}\right]=0.8, \\
\rho_{1}=\max \left\{\left\|I-R_{1} g_{1 x}(x(t)) B_{1}(x(t))\right\|,\right. \\
\left.\left\|I-R_{1} g_{2 x}(x(t)) B_{2}(x(t))\right\|\right\}=0.28
\end{gathered}
$$

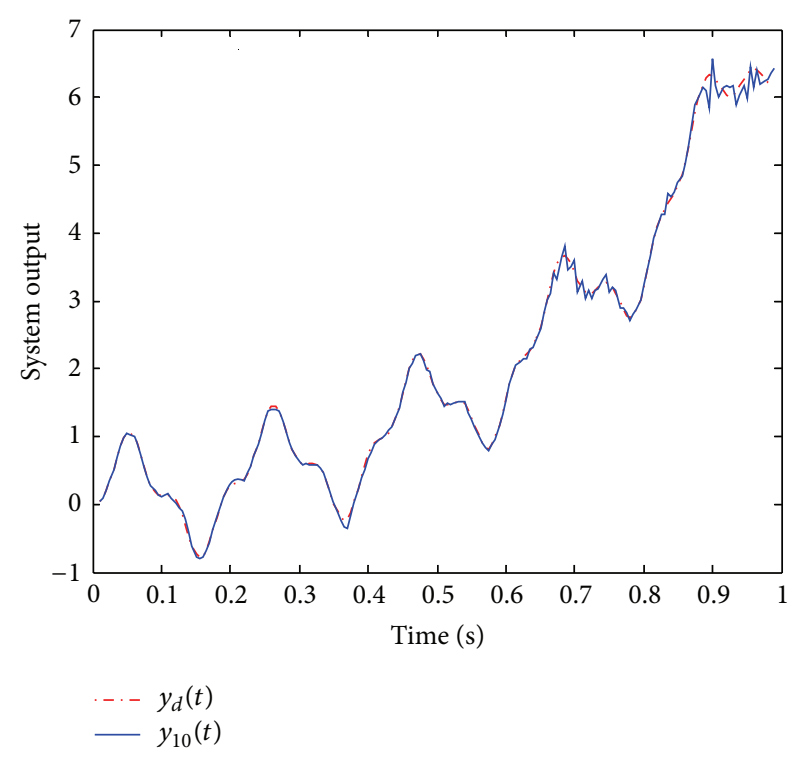

FIGURE 3: System output trajectory at 10th iteration for Example 1.

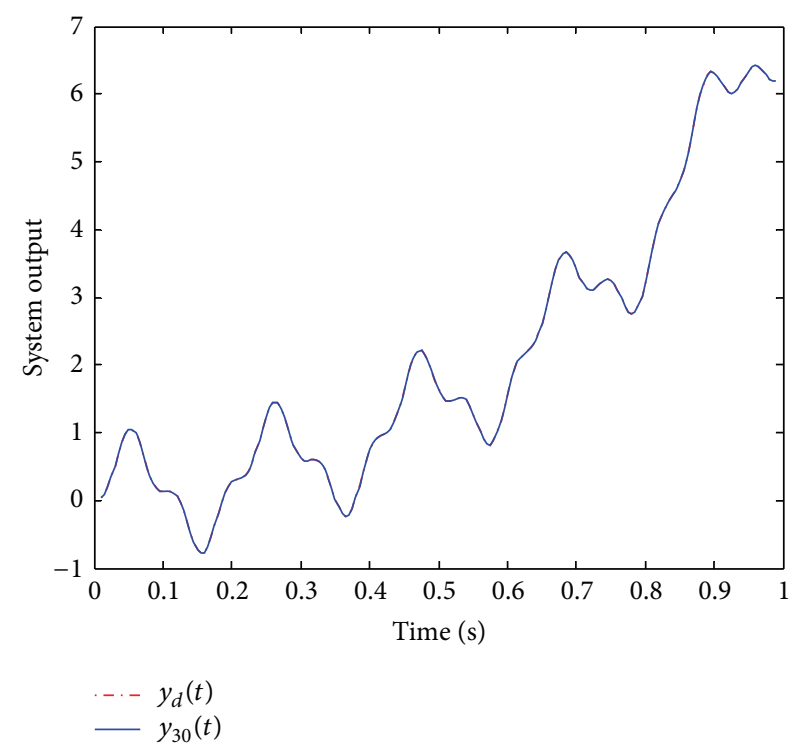

FIgURE 4: System output trajectory at 30th iteration for Example 1.

$$
\begin{gathered}
\rho_{2}=\max \left\{\left\|I-R_{2} g_{1 x}(x(t)) B_{1}(x(t))\right\|,\right. \\
\left.\left\|I-R_{2} g_{2 x}(x(t)) B_{2}(x(t))\right\|\right\}=0.2,
\end{gathered}
$$

then, $\rho_{1}+\rho_{2}=0.48<1$. From Theorem 9, we know that the nonlinear switched ILC system is asymptotically stable. Figures 2, 3, and 4 give simulation results for system output trajectories at 5th, 10th, and 30th iterations. In these figures, we plot the system output in solid line and the desired output trajectory in dashed line. It can be observed that the better tracking performance can be obtained after 30th iteration. Intuitively, this result can be understood in the following way: although the switched system has an arbitrary 


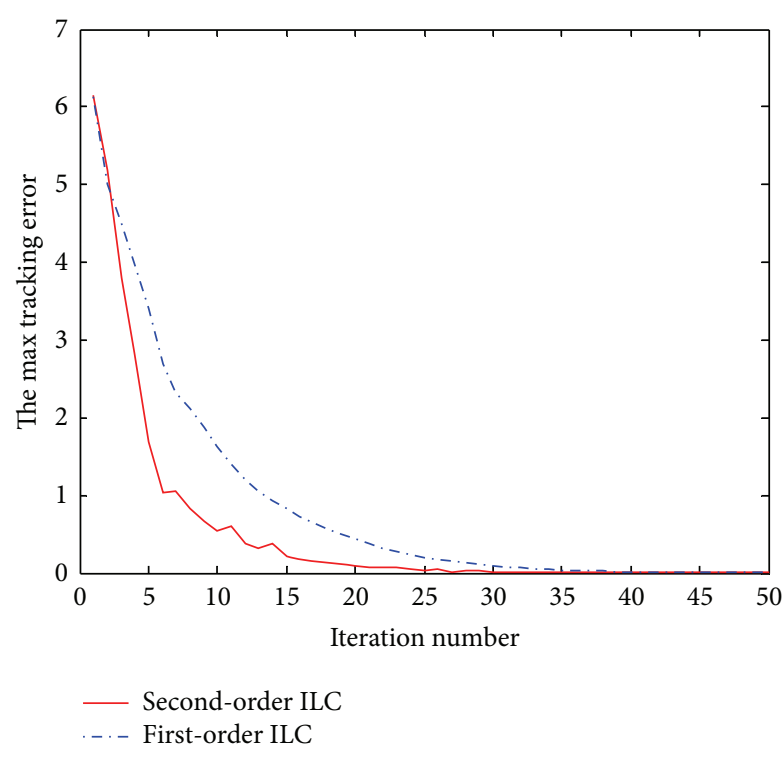

FIGURE 5: The max tracking error of Example 1 for different ILC laws.

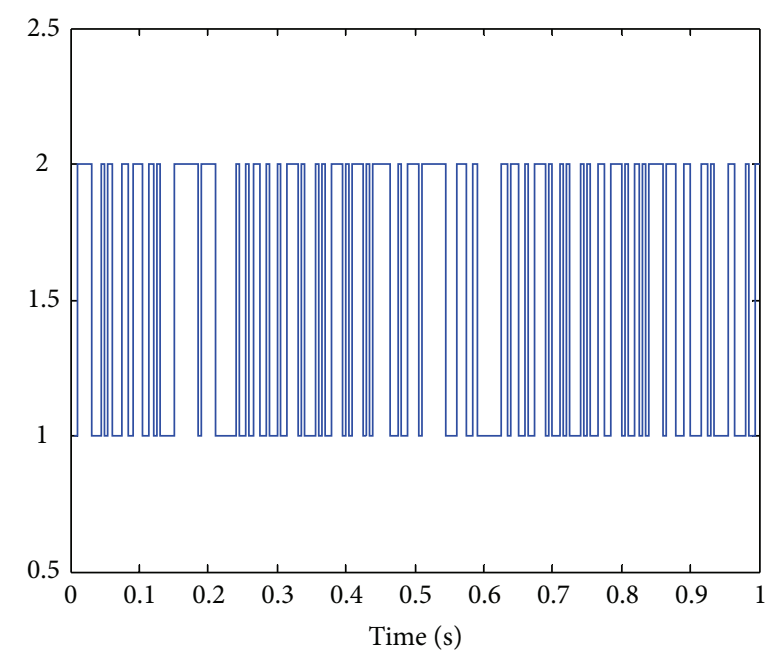

FIGURE 6: The random switched rule $\sigma(t)$ for system (2).

switched rule on the time domain, the arbitrary switched rule is invariable on the iteration domain. If we update the control signals on the repetitive iteration domain, the perfect tracking performance can be obtained eventually.

In this section, we consider two illustrative examples.

Example 1 (SISO nonlinear switched system). To further check the effectiveness of high-order ILC law, we also did simulation tests using first-order ILC given as $u_{k+1}(t)=$ $u_{k}(t)+0.6 e_{k}(t)+0.5 \dot{e}_{k}(t)$, and the control input at the first iteration is also given as $u_{0}(t)=0$ for all $t \in[0,1]$. The tracking errors for second-order ILC and first order ILC are given in Figure 5. Clearly, the high-order ILC scheme can be faster convergence than the first-order one.
Example 2 (MIMO nonlinear switched system with state delay). In this example, let us consider the following MIMO nonlinear switched system with time delay:

$$
\begin{aligned}
& S_{1}:\left\{\begin{array}{l}
{\left[\begin{array}{l}
\dot{x}_{1, k}(t) \\
\dot{x}_{2, k}(t)
\end{array}\right]} \\
=\left[\begin{array}{c}
0.5 x_{1, k}(t-h)+x_{2, k}(t) \\
0.3 x_{1, k}(t-h)+\frac{1}{1+x_{2, k}(t)}
\end{array}\right] \\
\quad+\left[\begin{array}{cc}
1 & 0 \\
\sin (t-d) x_{1, k}(t-d) & \cos (t-d) x_{2, k}(t-d)
\end{array}\right]
\end{array}\right. \\
& \times\left[\begin{array}{l}
u_{1, k}(t) \\
u_{2, k}(t)
\end{array}\right] \\
& {\left[\begin{array}{l}
y_{1, k}(t) \\
y_{2, k}(t)
\end{array}\right]=\left[\begin{array}{c}
\sin \left(x_{1, k}(t)\right)+0.1 x_{2, k}(t) \\
\cos \left(x_{2, k}(t)\right)
\end{array}\right] \text {, }} \\
& S_{2}:\left\{\begin{aligned}
{\left[\begin{array}{c}
\dot{x}_{1, k}(t) \\
\dot{x}_{2, k}(t)
\end{array}\right]=} & {\left[\begin{array}{c}
0.2 x_{1, k}(t)+x_{2, k}(t-h) \\
0.6 x_{1, k}(t)+\frac{1}{0.5+x_{2, k}(t-h)}
\end{array}\right] } \\
& +\left[\begin{array}{ll}
1 & \cos (t-d) x_{1, k}(t-d) \\
0 & \sin (t-d) x_{2, k}(t-d)
\end{array}\right]\left[\begin{array}{l}
u_{1, k}(t) \\
u_{2, k}(t)
\end{array}\right], \\
{\left[\begin{array}{l}
y_{1, k}(t) \\
y_{2, k}(t)
\end{array}\right]=} & {\left[\begin{array}{c}
0.3 x_{1, k}(t)+\sin \left(x_{2, k}(t)\right) \\
\cos \left(x_{1, k}(t)\right)
\end{array}\right], }
\end{aligned}\right.
\end{aligned}
$$

where $h=d=0.1$. The switched system is also operated during the two subsystems with arbitrary switched law in time domain, and the desired trajectories are given as

$$
\left[\begin{array}{l}
y_{1, d}(t) \\
y_{2, d}(t)
\end{array}\right]=\left[\begin{array}{l}
\sin 3 \pi t \\
\cos 3 \pi t
\end{array}\right], \quad t \in[0,1]
$$

For the initial state, it is assumed that $x_{1, k}(0)=x_{2, k}(0)=0$ for all $k$. The ILC law is applied by adopting the zero initial control input $u_{1,0}(t)=0, u_{2,0}(t)=0$, for all $t \in[0,1]$. In simulation, we produces a random sequence $\sigma(t)$, and $t \epsilon$ $[0,1]$ with the value is 1 and 2 , as shown in Figure 6 , If $\sigma(t)=1$, the system (2) is $S_{1}$; otherwise, if $\sigma(t)=2$, the system (2) is $S_{2}$. We consider the following second order ILC law:

$$
\begin{aligned}
u_{k+1}(t)= & u_{k}(t)+Q_{1} e_{k-1}(t)+Q_{2} e_{k}(t) \\
& +R_{1} \dot{e}_{k-1}(t)+R_{2} \dot{e}_{k}(t),
\end{aligned}
$$

where $Q_{1}=0.5, Q_{2}=0.4, R_{1}=0.8$, and $R_{2}=1.1$. Note that the nonlinear system only contains nonlinear argument $\sin (x), \cos (x)$, and they are both uniformly globally Lipschitz in $x$ and uniformly bounded for all $t \in[0,1]$. To guarantee the ILC convergence, $\rho$ should be less than one. It is easy to obtain that the previous choices of $R_{1}, R_{2}$ clearly satisfy the convergence condition. The simulation results for system output trajectories at 5th, 10th, and 30th iterations are shown in Figures 7, 8, and 9. In these figures, we plot the system output in solid line and the desired output trajectory in dashed line. It can be observed that the switched ILC system is asymptotically stable, and the better tracking performance can be obtained after 30th iteration for the whole time interval. We also did simulation tests using first order ILC 


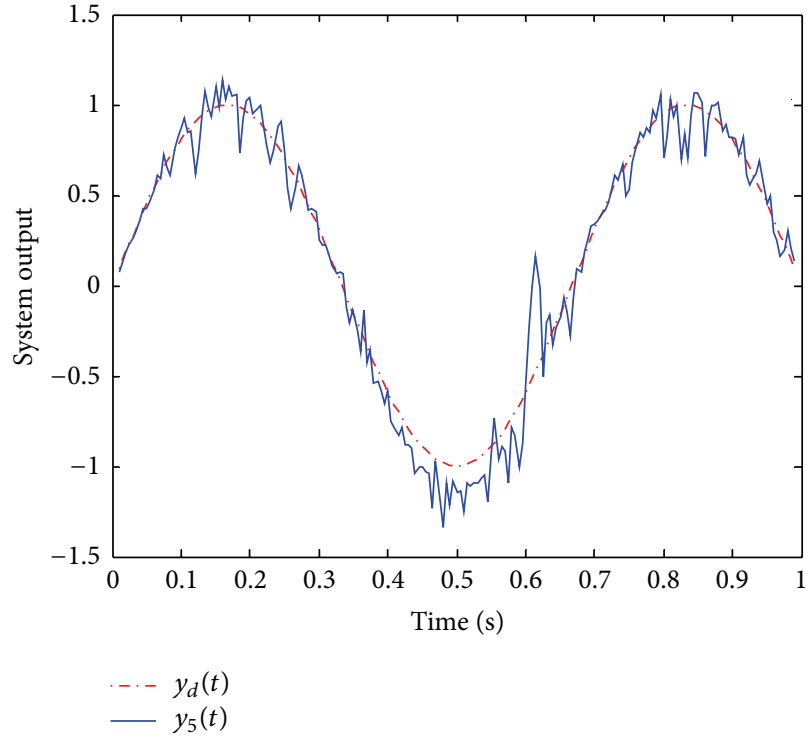

(a)

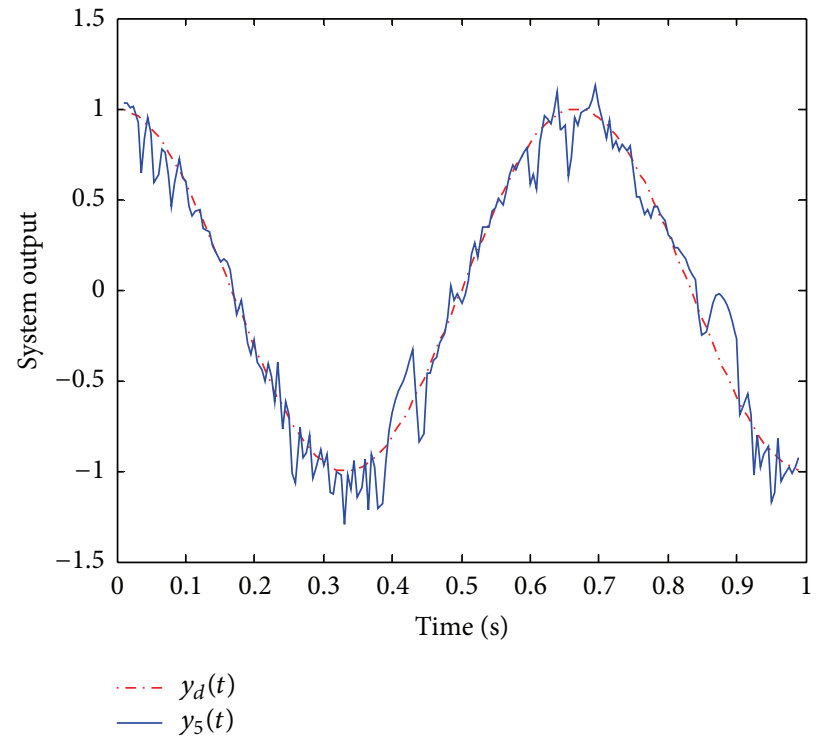

(b)

Figure 7: System output trajectory at 5th iteration for Example 2: (a) $y_{1, k}(t)$, (b) $y_{2, k}(t)$.

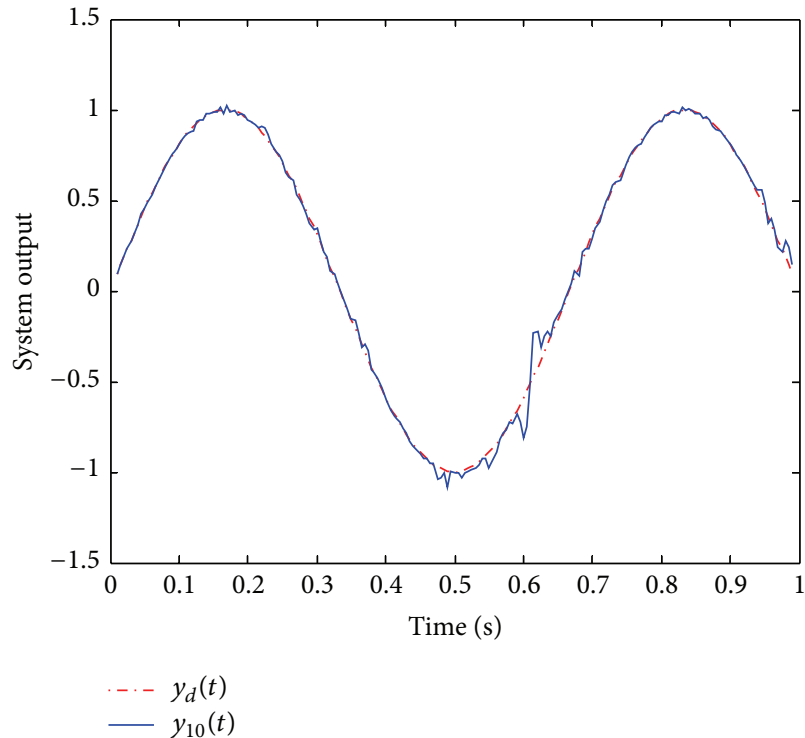

(a)

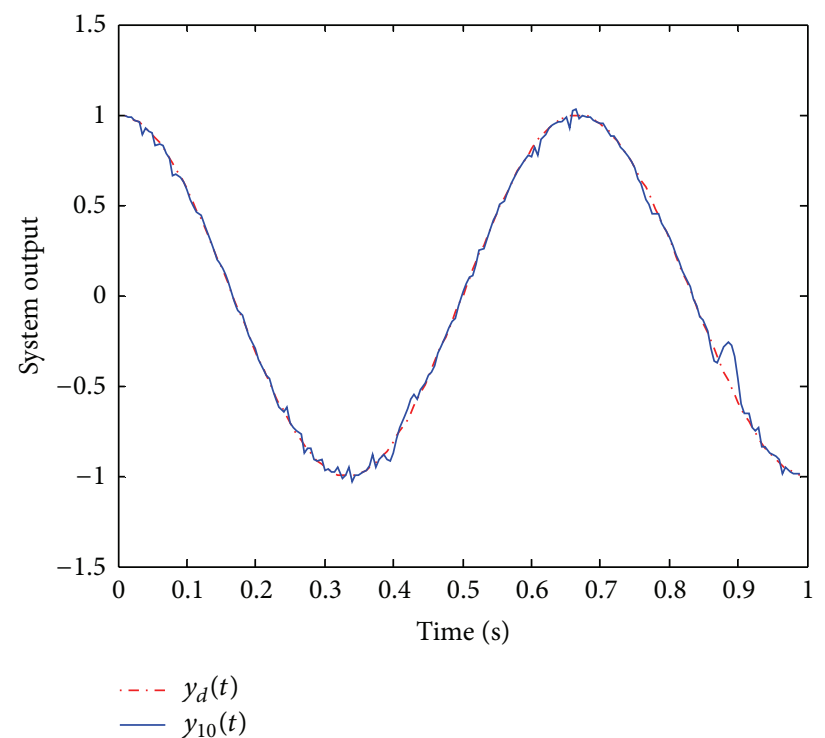

(b)

FIGURE 8: System output trajectory at 10th iteration for Example 2: (a) $y_{1, k}(t)$, (b) $y_{2, k}(t)$.

given as $u_{k+1}(t)=u_{k}(t)+0.6 e_{k}(t)+0.5 \dot{e}_{k}(t)$, and the control input at the first iteration is also given as $u_{1,0}(t)=0, u_{2,0}(t)=$ 0 , for all $t \in[0,1]$. The simulation results of tracking errors for second order ILC and first order ILC are shown in Figure 10. It is presented to illustrate the effectiveness of high-order ILC law over the conventional first-order one.

\section{Conclusions}

The stability of high-order ILC law for nonlinear switched systems with state delays is analyzed. It is shown that the asymptotic convergence of the tracking error can be guaranteed under some conditions, and the perfect tracking performance can be obtained during the entire time interval. This result can be understood in the following way: although the switched system has an arbitrary switched rule on the time domain, the arbitrary switched rule is invariable on the iteration domain. If we update the control signals on the repetitive iteration domain, the perfect tracking performance can be obtained eventually.

In the previous works [20-22], the asymptotic convergence of tracking control is only guaranteed in the time 


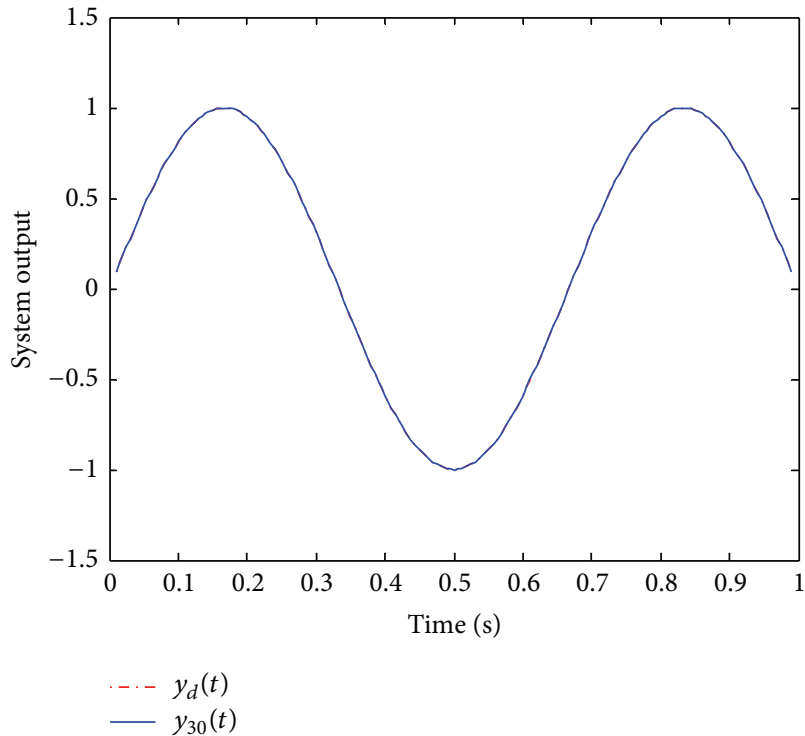

(a)

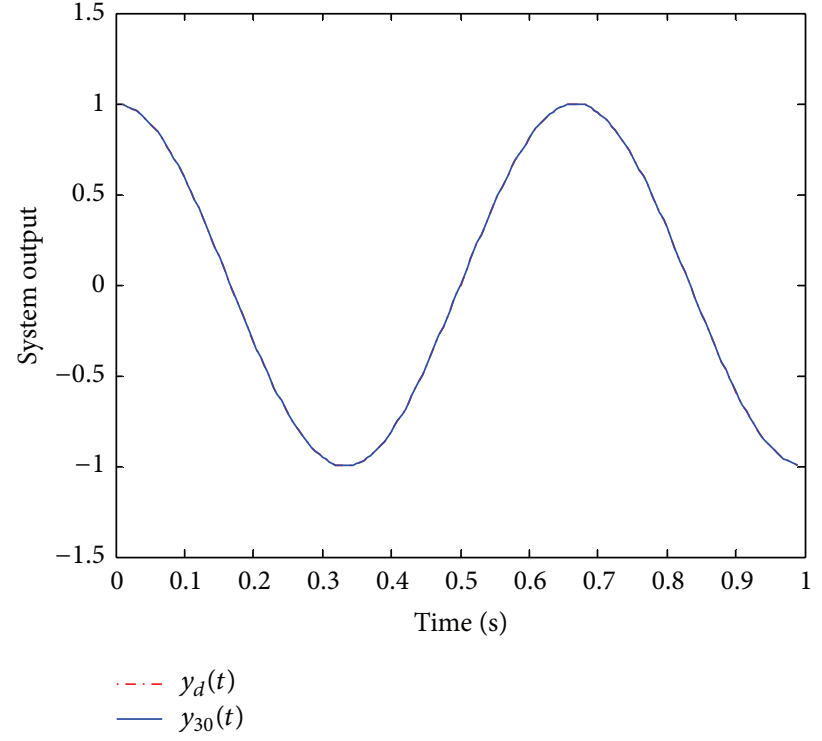

(b)

FIGURE 9: System output trajectory at 30th iteration for Example 2: (a) $y_{1, k}(t)$, (b) $y_{2, k}(t)$.

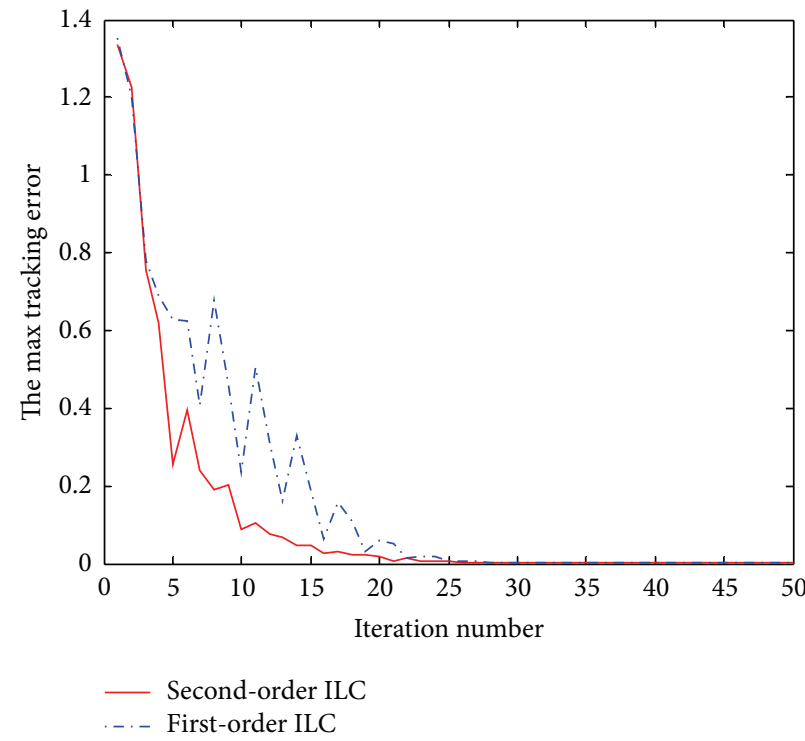

(a)

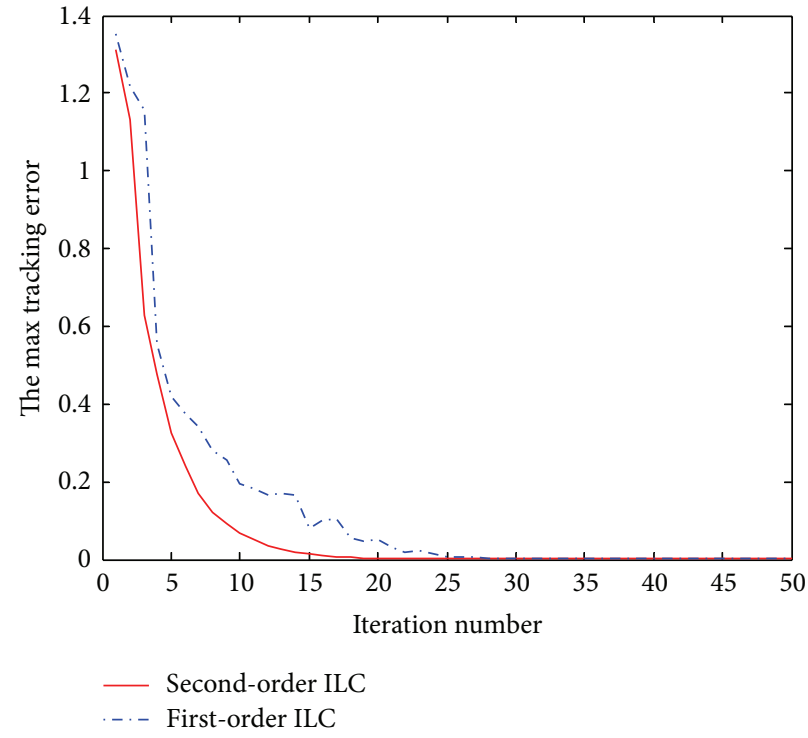

(b)

FIGURE 10: The max tracking error of Example 2 for different ILC laws: (a) $e_{1, k}(t),(\mathrm{b}) e_{2, k}(t)$.

domain; that is, the system output tracking errors converge to 0 when $t \rightarrow \infty$. When the ILC is considered for switched systems, the perfect tracking performance can be obtained during the entire time interval. ILC can use the previous operation information of the switched systems, and then the tracking can be performed better progressively from operation to operation. It also requires less a priori knowledge about the system dynamics and less computational effort than many other kinds of control approaches. In future work, we will consider the stability of nonlinear switched systems with arbitrary switched rule on the iteration domain.

\section{Acknowledgments}

This work is supported by the Program of NSFC (no. 61203065, no. 61240049), the Program of Open Laboratory Foundation of Control Engineering Key Discipline of Henan 
Provincial High Education (KG 2011-10), and the Program of Key Young Teacher of Henan Polytechnic University.

\section{References}

[1] D. Liberzon and A. S. Morse, "Basic problems in stability and design of switched systems," IEEE Control Systems Magazine, vol. 19, no. 5, pp. 59-70, 1999.

[2] D. Liberzon, Switching in Systems and Control, Systems \& Control: Foundations \& Applications, Birkhäuser, Boston, Mass, USA, 2003.

[3] Z. Sun and S. S. Ge, Switched Linear Systems: Control and Design, Springer, New York, NY, USA, 2005.

[4] D. K. Kim, P. Park, and J. W. Ko, "Output-feedback $\mathscr{H}_{\infty}$ control of systems over communication networks using a deterministic switching system approach," Automatica, vol. 40, no. 7, pp. 12051212, 2004.

[5] H. Lin and P. J. Antsaklis, "Stability and persistent disturbance attenuation properties for a class of networked control systems: switched system approach," International Journal of Control, vol. 78, no. 18, pp. 1447-1458, 2005.

[6] R. Horowitz and P. Varaiya, "Control design of an automated highway system," Proceedings of the IEEE, vol. 88, no. 7, pp. 913925, 2000.

[7] P. Antsaklis, "Special issue on hybrid systems: theory and applications-a brief introduction to the theory and applications of hybrid systems.," Proceedings of the IEEE, vol. 88, no. 7, pp. 887-897, 2000.

[8] J. P. Hespanha and A. S. Morse, "Switching between stabilizing controllers," Automatica, vol. 38, no. 11, pp. 1905-1917, 2002.

[9] H. Ishii and B. A. Francis, "Stabilizing a linear system by switching control with dwell time," IEEE Transactions on Automatic Control, vol. 47, no. 12, pp. 1962-1973, 2002.

[10] M. S. Branicky, "Multiple Lyapunov functions and other analysis tools for switched and hybrid systems," IEEE Transactions on Automatic Control, vol. 43, no. 4, pp. 475-482, 1998.

[11] A. N. Michel, "Recent trends in the stability analysis of hybrid dynamical systems," IEEE Transactions on Circuits and Systems. I, vol. 46, no. 1, pp. 120-134, 1999.

[12] D. Liberzon, J. P. Hespanha, and A. S. Morse, "Stability of switched systems: a Lie-algebraic condition," Systems \& Control Letters, vol. 37, no. 3, pp. 117-122, 1999.

[13] J. Zhao and G. M. Dimirovski, "Quadratic stability of a class of switched nonlinear systems," IEEE Transactions on Automatic Control, vol. 49, no. 4, pp. 574-578, 2004.

[14] H. Lin and P. J. Antsaklis, "Stability and stabilizability of switched linear systems: a survey of recent results," IEEE Transactions on Automatic Control, vol. 54, no. 2, pp. 308-322, 2009.

[15] Z. Ji, L. Wang, and X. Guo, "Design of switching sequences for controllability realization of switched linear systems," Automatica, vol. 43, no. 4, pp. 662-668, 2007.

[16] D. Cheng, "Controllability of switched bilinear systems," IEEE Transactions on Automatic Control, vol. 50, no. 4, pp. 511-515, 2005.

[17] J. P. Hespanha, D. Liberzon, D. Angeli, and E. D. Sontag, "Nonlinear norm-observability notions and stability of switched systems," IEEE Transactions on Automatic Control, vol. 50, no. 2, pp. 154-168, 2005.

[18] Z. Sun and S. S. Ge, "Analysis and synthesis of switched linear control systems," Automatica, vol. 41, no. 2, pp. 181-195, 2005.
[19] H. Liu and Y. Shen, "Asynchronous finite-time stabilisation of switched systems with average dwell time," IET Control Theory \& Applications, vol. 6, no. 9, pp. 1213-1219, 2012.

[20] Q.-K. Li, J. Zhao, and G. M. Dimirovski, "Tracking control for switched time-varying delays systems with stabilizable and unstabilizable subsystems," Nonlinear Analysis: Hybrid Systems, vol. 3, no. 2, pp. 133-142, 2009.

[21] Q.-K. Li, J. Zhao, X.-J. Liu, and G. M. Dimirovski, "Observerbased tracking control for switched linear systems with timevarying delay," International Journal of Robust and Nonlinear Control, vol. 21, no. 3, pp. 309-327, 2011.

[22] B. Niu and J. Zhao, "Tracking control for output-constrained nonlinear switched systems with a barrier Lyapunov function," International Journal of Systems Science, vol. 44, no. 5, pp. 978985, 2013.

[23] S. Arimoto, S. Kawamura, and F. Miyazaki, "Bettering operation of robots by learning.," Journal of Robotic Systems, vol. 1, no. 2, pp. 123-140, 1984.

[24] H. S. Ahn, Y. Chen, and K. L. Moore, "Iterative learning control: brief survey and categorization.," IEEE Transactions on Systems, Man, and Cybernetics Part C, vol. 37, no. 6, pp. 1099-1121, 2007.

[25] R. Chi, Z. Hou, and J. Xu, "Adaptive ILC for a class of discretetime systems with iteration-varying trajectory and random initial condition," Automatica, vol. 44, no. 8, pp. 2207-2213, 2008.

[26] M. Sun and D. Wang, "Initial shift issues on discrete-time iterative learning control with system relative degree," IEEE Transactions on Automatic Control, vol. 48, no. 1, pp. 144-148, 2003.

[27] Z. Hou, J.-X. Xu, and J. Yan, "An iterative learning approach for density control of freeway traffic flow via ramp metering," Transportation Research Part C, vol. 16, no. 1, pp. 71-97, 2008.

[28] W. Chen, J. Li, and J. Li, "Practical adaptive iterative learning control framework based on robust adaptive approach," Asian Journal of Control, vol. 13, no. 1, pp. 85-93, 2011.

[29] W. Chen and L. Zhang, "Adaptive Iterative learning control for nonlinearly parameterized systems with unknown timevarying delays," International Journal of Control, Automation and Systems, vol. 8, no. 2, pp. 177-186, 2010.

[30] X. Bu, F. Yu, Z. Hou, and F. Wang, "Iterative learning control for a class of nonlinear systems with random packet losses," Nonlinear Analysis: Real World Applications, vol. 14, no. 1, pp. 567-580, 2013.

[31] S. Andrei, J. Diblik, K. Denys, and M. Ruzickova, "Stabilization of Lur'e-type nonlinear control systems by Lyapunov-Krasovskii functionals," Advances in Difference Equations, vol. 2012, 9 pages, 2012.

[32] I. A. Dzhalladova, J. Baštinec, J. Diblík, and D. Y. Khusainov, "Estimates of exponential stability for solutions of stochastic control systems with delay," Abstract and Applied Analysis, vol. 2011, Article ID 920412, 14 pages, 2011.

[33] J. Diblík, D. Ya. Khusainov, and M. Růžičková, “Controllability of linear discrete systems with constant coefficients and pure delay," SIAM Journal on Control and Optimization, vol. 47, no. 3, pp. 1140-1149, 2008.

[34] Y. Chen, Z. Gong, and C. Wen, "Analysis of a high-order iterative learning control algorithm for uncertain nonlinear systems with state delays," Automatica, vol. 34, no. 3, pp. 345353, 1998.

[35] T. M. Flett, Differential Analysis, Cambridge University Press, Cambridge, UK, 1980. 
[36] Y. Shen and J. Wang, "Noise-induced stabilization of the recurrent neural networks with mixed time-varying delays and Markovian-switching parameters," IEEE Transactions on Neural Networks, vol. 18, no. 6, pp. 1857-1862, 2007.

[37] Y. Shen and J. Wang, "Almost sure exponential stability of recurrent neural networks with Markovian switching," IEEE Transactions on Neural Networks, vol. 20, no. 5, pp. 840-855, 2009.

[38] Y. Shen and J. Wang, "Robustness analysis of global exponential stability of recurrent neural networks in the presence of time delays and random disturbances," IEEE Transactions on Neural Network, vol. 23, no. 1, pp. 87-96, 2012.

[39] S. S. Saab, W. G. Vogt, and M. H. Mickle, "Learning control algorithms for tracking "slowly" varying trajectories," IEEE Transactions on Systems, Man, and Cybernetics, Part B, vol. 27, no. 4, pp. 657-670, 1997.

[40] D. Wang, "Convergence and robustness of discrete time nonlinear systems with iterative learning control," Automatica, vol. 34, no. 11, pp. 1445-1448, 1998. 


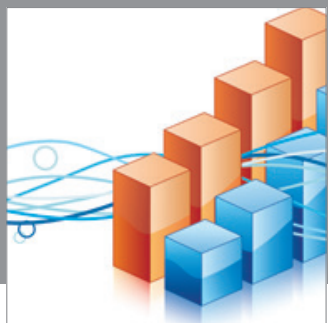

Advances in

Operations Research

mansans

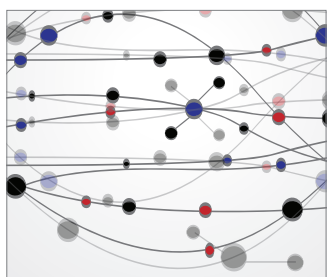

The Scientific World Journal
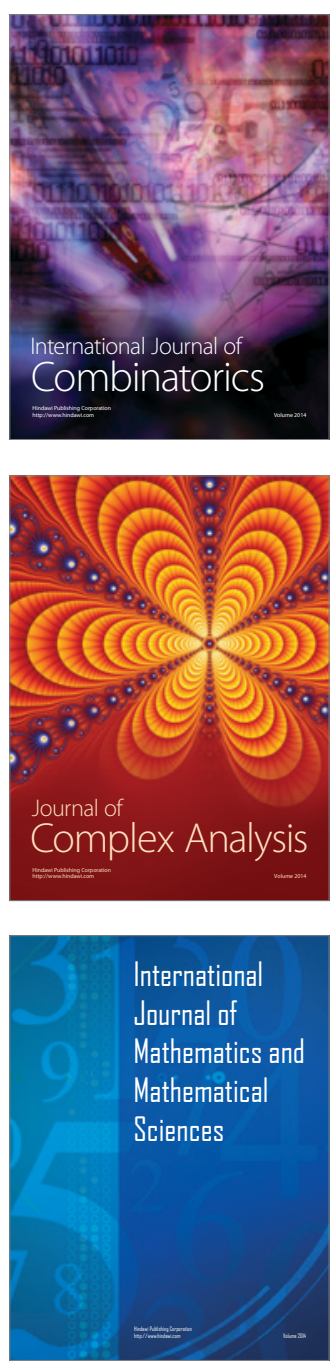
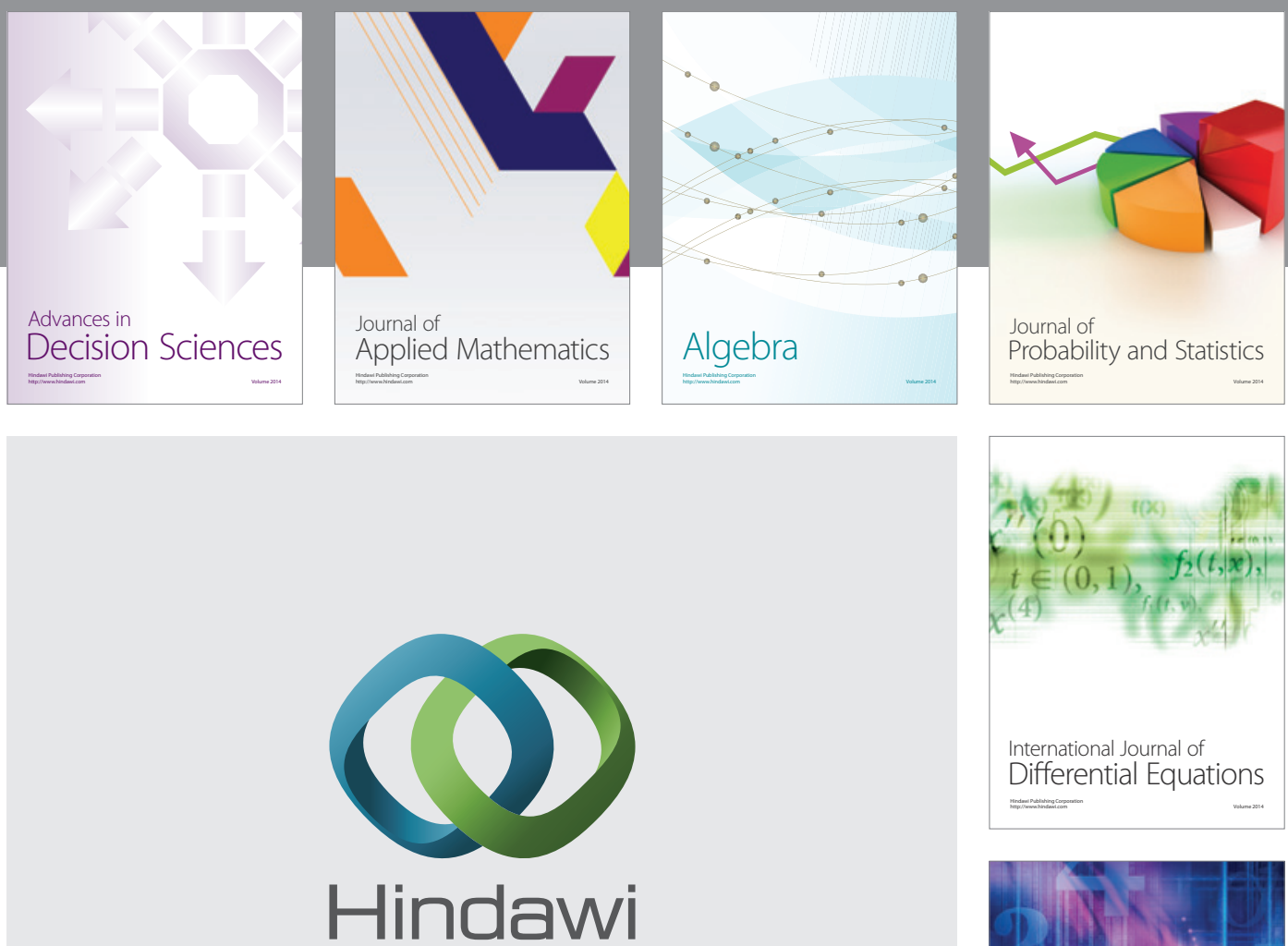

Submit your manuscripts at http://www.hindawi.com
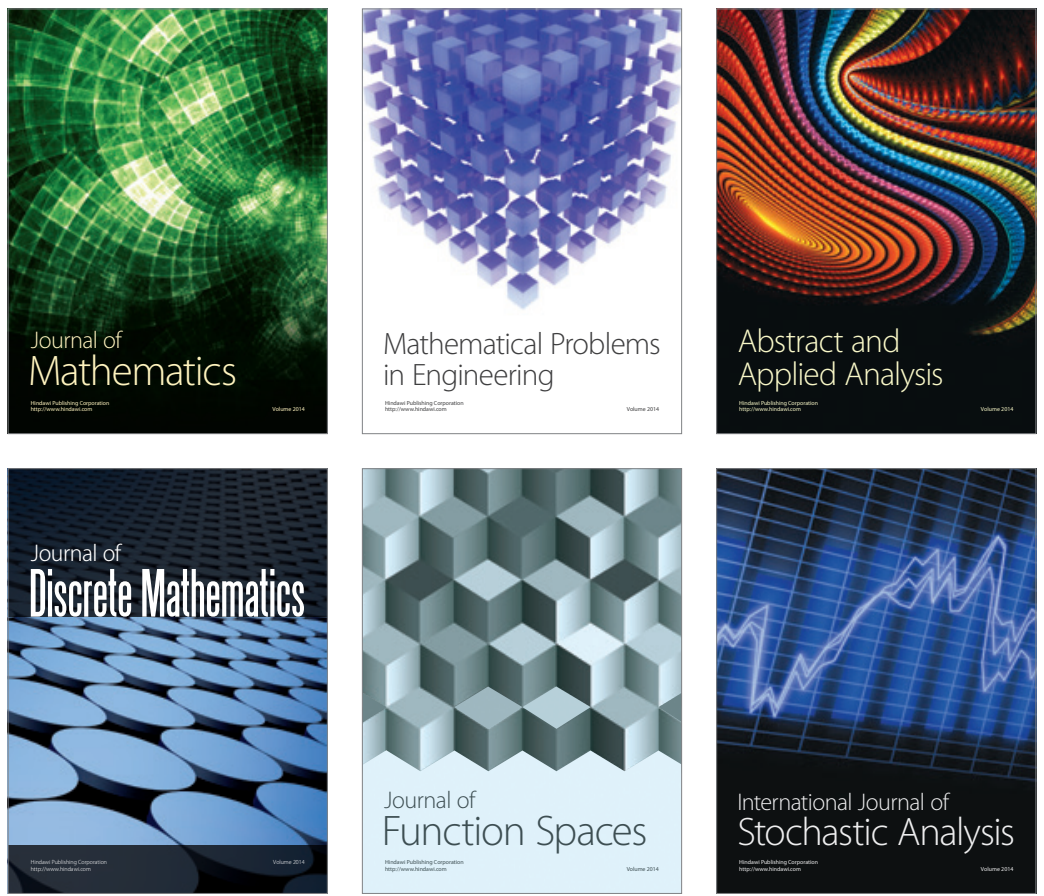

Journal of

Function Spaces

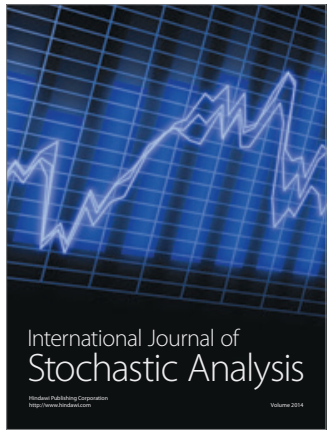

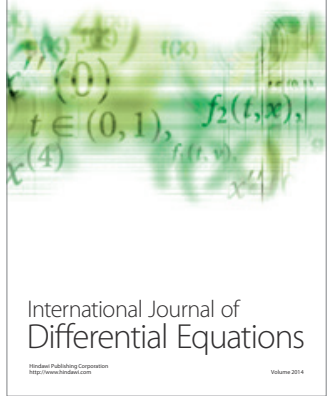
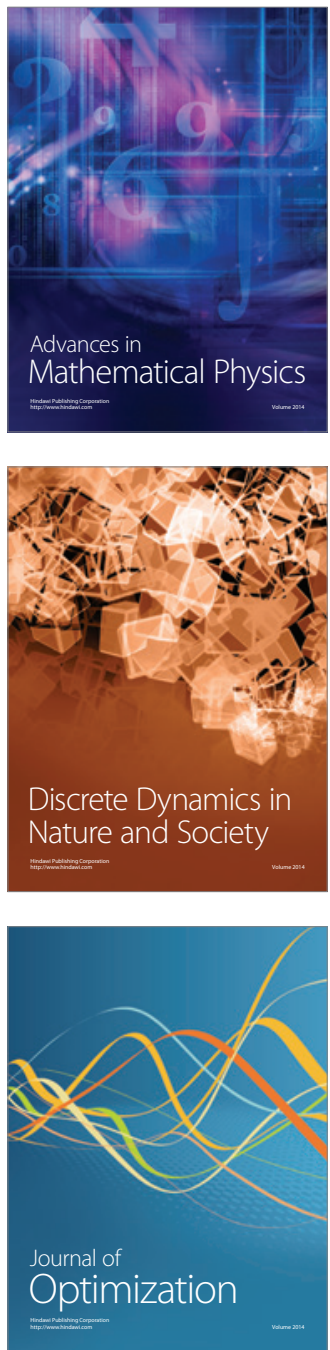